\title{
Research on the integrated development of marginal characteristic villages from the perspective of popular science tourism
}

\author{
Qiang Liu ${ }^{1}$, Hanfang Liu ${ }^{1, *}$ \\ ${ }^{1}$ School of Civil Engineering and Architecture, University of Jinan, Jinan, China
}

\begin{abstract}
Since the government elevated the rural revitalization strategy to the national level in 2018 , the rural revitalization work has been effectively promoted and developed across the country, but there is a "double-edge" rural type that deserves attention. They are on the edge of social attention and investment because they are not listed in the List of Traditional Villages or Beautiful Village, and they often have great potential for tourism development by virtue of geographical advantages, rich regional resources and unique cultural resources. This paper focuses on the tourism integration planning and development of this kind of "double-edge" villages. From the micro-scale of the village, combined with the rural revitalization, this paper takes the ancient village of Zhengjiawopo in Jinan as the specific foothold to carry out the planning pilot study.After nearly two years of theoretical research and practical exploration by a multidisciplinary planning team,with the beep nest village planning and development results of the initial slope.
\end{abstract}

\section{Introduction}

According to the statistics of the "List of China's Traditional Villages," there are 4153 villages that have been included in the List since 2012[1]. In addition to the state and local governments' vigorous support, these traditional villages still retain their unique resources, including rich natural landscapes, cultural landscapes, and intangible cultural heritage resources. They are historical memories and reflect civilization's progress, but not included in the List for various reasons. This type of village stays in a marginal state with little social concern but is located near cities. They may get support from the welfare radiation of cities but are often on the verge of being forgotten; despite their rich geomorphic resources and heavy historical and cultural accumulation, they has yet to be recognized and win certain official title(s), when staying in embarrassment; meanwhile, they, like some traditional villages, are generally facing a series of problems such as the empty nesting of villages, the stylized development, the homogenization of commerce, and the marginalization of villagers in terms of benefits. It will take restoring prosperity to villages that have languished; It needs to combine the profound historical context with planning and tourism. Attention needs to be paid to the participation of villagers in building new villages. Compared with the researches on universal rural development, the study on a certain representative case of rural development of distinctive features is of great significance. This paper intends to take the practical exploration of Zhengjiawopo Village in the suburbs of Jinan as an example. While leveraging the advantages of location and regional resources and taking advantage of urban and suburban integration development and rural revitalization, we aim to carry out the integrated planning research on characteristic industries, rural tourism, architectural renewal, and landscape enhancement to explore the diversified integrated development path of distinctive villages from both theoretical and practical exploration levels, and to construct a sustainable rural development system based on harmonious and healthy genes[2].

\section{Current universal problems in the development of villages}

\subsection{Simple and rude development mode}

The Chinese villages are diverse in type and uneven development foundation and multi-level support intensity. The development of villages with distinctive characteristics and rich history, should be steadily promoted according to local conditions, instead of simply copying the "standard model" while ignoring regional differences, not to mention the rude denial of rural native genes and endogenous self-renewal mechanism. In recent years, movements like "Ancient City Fever", "Ancient Village Movement", and undifferentiated copying of universal models such as the "Yuanjia Village" model, have led to serious homogeneity of landscape development in various regions, resulting in a loss of regionality. The Lantian County government, Shaanxi Province, announced in May 2020 the demolition of the Bailuyuan Folk Culture Village that cost 350 million yuan

\footnotetext{
*Corresponding author: 848205366@qq.com
} 
in construction, a move vaguely marking the failure of the undifferentiated "copying of ancient villages" in China.

\subsection{In lack of integrated planning and implementation}

The tourism planning of ancient villages often pays too much attention to the tourism itself and the rate of return. Still, it ignores the study on the integration degree of multiple elements in the overall development like rural industry, local culture, villagers' participation, etc. The analysis of various "compatibility" in rural development in terms of supply and demand of various parties is in short, leading to the uneven development of different development sectors that cannot interact with each other as a result.

\subsection{Villagers' poor participation}

In the new construction of rural areas in recent years, the village-led model of "township-village governance" has gradually become unbalanced. The "strong governance" of the government and foreign investment groups has led to the continuous decline of villagers' voice and participation. While issues like "de-localization" and the tendency of "aborigine's loss" are deteriorating, unable to activate the endogenous power of villagers, and the migration of villagers, on the other hand, cannot demonstrate the strong flavor of rural production and life rooted in the depth of the specific region.

\subsection{Destruction of endogenous rural mechanism}

In the face of the promotion of various rural construction projects in recent years, excessive pursuit of economic benefits has led to an obvious game between economic development and protection of village civilization. The destruction of rural historical remains, the loss of rural memories, and the collapse of rural cultural heritage, all have led to the loss of the distinctive features of specific villages.

\section{Current status and problems}

\subsection{Overview of Zhengjiawopo Village}

Zhengjiawopo Village, located in the southern suburbs of Jinan City, acts as the radiable hinterland resources of Jinian, and is rich in characteristic landform resources, vernacular architecture resources, and tourism resources. The village sits on the back of mountains facing waters, rich in natural resources with many scenic spots and scattered gushing springs. The houses therein are piled up with local stones, the majority of which were built during the late Qing Dynasty and the Republic of China.

With the progress of productive relations, it is difficult for traditional villages to adapt to the new functional needs of the society in the new era, which gradually lie waste thereby[3]. Zhengjiawopo Village is no exception.

With the changes of the times, the originally bustling and prosperous village has become quiet and desolate. Its original planning layout and spatial structure of the houses are no longer suitable for the living and production needs of contemporary people, and the ancient villages built in the middle of the Qing Dynasty are now ruined and empty.

\subsection{Advantages and constraints in development}

\subsubsection{Development advantages}

The unique natural resources and geographic location of Zhengjiawopo Village are advantageous for developing economy, and serve as the foundation of driving force for the development of rural tourism economy[4]. The village is rich in resources, as follows:

a) Location and transportation advantages. It is 26 kilometers away from the downtown of Jinan and falls into the category of one-hour tourism economic circle, which is attractive to the urban consumer groups. Relying on its 72 famous springs and millennium ginkgo trees adjacent to Jinan City, it has the advantage of developing regional tourism in blocks.

b) Regional geomorphology and climate advantages. Located in a mountainous area, its more complex topography and river system have created a diverse landscape of mountains, waters, forests, fields and lakes [5]; its beautiful scenery and rich vegetation, coupled with its climate warm in winter and cool in summer, have made it suitable for living and traveling.

c) Regional cultural and historical advantages. The overall spatial layout of the village and the organization of traffic flow lines are organic and natural, and the human settlement unit is highly compatible with the geographical unit. The vernacular architecture style together with the stone houses built in the Qing Dynasty has fully demonstrated the regional construction pattern, exuding a unique regional culture and the characteristics of that times.

\subsubsection{Constraints to development}

a) A lack of capital. Because it is not included in the List of China's Traditional Villages and the "beautiful countryside" project, its development is highly restrained by the limited government support funds and cautious private investment, which has restricted the scale and speed of the rural development.

b) A lack of industries. In rural revitalization, industry takes precedence. Zhengjiawopo Village lacks leading industries, and its characteristic industrial resources of natural endowments are yet to be explored and utilized. The lack of industries affects the rural economic development and the endogenous cohesion of villagers.

c) "Singularity". The prosperous development of the village requires the cooperation and integration of multiple disciplines and fields, and the "singularity" of development restricts the balanced development of the village and brings about problems of imbalance.

d) Villagers' participation. Under the guidance of national policy and the active promotion of the local 
government, the township construction practices promoted by various entities have emerged one after another, but the dominant position of the aborigines is mostly deprived. The reconstructed villages have become cultural tourism products shaped by various capitals. The approach of putting the aborigines to the periphery or into limited participation will get the endogenous power of the village lost, and thereby the strongest regional and rural life and production atmosphere is bound to get lost, which is to be replaced by the homogeneous production mode and display method.

\section{Development positioning}

\subsection{Overall goal}

Focusing on the overall prosperity of Zhengjiawopo Village, we will take the advantage of the rural revitalization strategy proposed in China and the transformation of new and old kinetic energy proposed by the provincial party committee and government to integrate rural planning, rural tourism, building renewal, landscape enhancement, and rural industries into the overall organic framework for rural development. The integration of knowledge popularization, characteristic industries and leisure and tourism, aims to accelerate the construction of a new rural area based on planning and dominated by industry + tourism. Coupled with a macro planning and design plan, as well as a micro implementation plan, we are to take a road of differentiation to revitalize the characteristic village based on local conditions.

\section{Case exploration on the planning}

\subsection{Integration of diversity, sharing and win-win cooperation}

Rural construction should encourage diversified subjects to participate and adopt diversified perspectives to promote the deep integration of multi-functions of agriculture, with a view to pushing forward the deep participation of indigenous people in rural construction and project development and in return making them enjoy the dividends brought by rural development. The diversified and integrated perspectives of rural construction are also reflected in the integration of the concepts of beautiful countryside construction and pastoral complexes, as well as the integration of the cultural, industrial and ecological sectors of rural revitalization into the overall planning of the ancient village. This is a way to realize the overall planning and cross-penetration of agriculture and animal husbandry, tourism, culture, architectural renewal, and popular science popularization, striving to achieve multi-party sharing and win-win cooperation. Based on the preliminary detailed investigation of Zhengjiawopo Village, the planning team carried out feasibility planning and reasonable functional zoning of the ancient village to create a themed homestay zone characterized by medicinal bath, a tourist service zone, a site park to popularize the heritage, and a sightseeing zone, and a planting zone of its own characteristics.

\subsection{Creating rural tourism with the theme of science popularization}

Rural tourism characterized by science popularization is based on the diverse tourism resources in the countryside. Through planning and design with tourism connotation, rural construction, rural industry, rural culture, science and knowledge popularization and the extensive participation of tourists are integrated into a unity.

The axis of Zhengjiawopo Village tourism characterized by science popularization runs through the historical relics section, the cultural landscape section, the characteristic industry section, and the handicraft processing section. The axis of "medical science popularization" has been adopted to connect industrial sections of themed homestay zone characterized by medicinal bath and Chinese herbal medicine planting, etc.; The axis of "cultural science popularization" has been adopted to carry out knowledge and science popularization of the native style and construction technology of the remaining buildings; The axis of "plant identification and efficacy awareness" has been adopted to connect Chinese herbal medicine base, beekeeping base, and special agricultural products processing base.

Popularization of historical relics and human landscape: the existing buildings from the Qing Dynasty, the Republic of China, the initial post-liberation period, the Cultural Revolution, and the 1980s till the contemporary era, are themselves a history book to popularize the living vernacular architecture style with times in Zhengjiawopo Village. The architectural styles therein have been marked by the times. The different building materials and masonry methods that differ reflect the advancement of science and technology and the needs of the times. The changes in the architectural space pattern reflect the increasing living and production needs of the villagers with the development of the times.

Tourism science popularization of characteristic industries and processing sectors: constructing the Chinese herbal medicine cultivation base, the agricultural products planting base of its own characteristics, the honey and grasshopper breeding bases, and developing plant identification and efficacy awareness to popularize Chinese herbal medicine; planting and breeding industries like hickory, Gongju growing, and grasshopper breeding, serve to provide sites for sightseeing or picking and nutrition knowledge popularization.

\subsection{Renewal of the remaining vernacular buildings}

For the functional expansion of the remaining vernacular buildings, we should get them integrated with the local characteristic planting and breeding industries including Chinese herbal medicine and Gongju planting and honey bee breeding, to create a themed homestay of medicinal bath, a health care-themed homestay, and a science 
popularization-themed homestay, enabling the collaborative and innovative fusion of characteristic breeding industries and homestay accommodation, science popularization tourism in development.

The renewal and transformation of the remaining vernacular buildings are supposed to be taken in different ways in line with the specific conditions.

a) As for the relatively well-preserved village buildings, reinforcement, repair and restoration are the major measures to be taken to show their original vernacular appearance to the maximum.

b) As for locally damaged village buildings (such as those with missing roofs or walls), in addition to strengthening and repairing, contemporary design elements, such as floor-to-ceiling window glass, section steel, and wood, should be properly implanted, so that ancient building materials and construction techniques, could collide with their contemporary counterparts in time and space to get tradition and modernity fully fused.

c) As for the badly damaged village buildings only with broken walls and relics left, we could rebuild a new Chinese-style homestay on the original site. The broken walls left and remaining building components can be used as ornamental decorations of the homestay as appropriate to increase the original memory of the site and to disseminate knowledge on traditional vernacular construction techniques.

\subsection{Improving rural endogenous force}

It's necessary to elaborate the processes and modes of village development planning, and to increase the participation of indigenous people in discussions, decision-making, and industrial processes, so as to break through the actual dilemma for indigenous people to get involved in the rural planning development and new industries. In drawing lessons from the strategy of "enhancing rights" adopted by Xidi Village, Anhui Province to "empower" the indigenous people, and motivate them to participate in cooperation and profit distribution, in terms of characteristic industries such as hickory, grasshopper breeding and Gongju planting industries, homestay property services, rural tourism instruction, Chinese herbal medicine identification and efficacy popularization, and the popularization of ancient building construction techniques. This is way to balance the interests of all parties and stimulate the endogenous power of the villagers.

\section{Characteristic advantages}

Exploiting and utilizing regional resources to create a unique rural landscape axis is essential. Along the landscape axis, three points need to be highlighted. Firstly, to strengthen the restoration of rural architecture, and to intensify the recognizability and regional differentiation of the rural architecture; Secondly, to plant more cash crops such as pumpkin, loofah, gourd, jujube, together with flowers such as rose, peony, potted lotus, etc., to create multi-level, full-space characteristic landscape corridors with micro-landscapes of crops scattered at the path nodes; Thirdly, to plant persimmon, hawthorn, mountain apricot, and pine trees on both sides of the main road leading to the village to create a fruit tree landscape village road.

\section{Conclusion}

Since the strategy of rural revitalization was first proposed for national development in 2018, it has undergone steady progress in 2018 and 2019, and now entered the critical stage of surmounting difficulties and also promoting substantive construction. This study focuses on the rural development of special characteristics, with the renewal and development of Zhengjiawopo Village as the entry point. While fully relying on its geographical location advantages and unique regional resource endowments, the Zhengjiawopo Village has displayed its exemplary and motivating role by adopting the step-by-step development: taking measures according to local conditions and regional resources, and putting forward a feasible planning scheme together with specific plans for implementation. Its planning has placed great emphasis on stimulating the endogenous power and positive momentum of the indigenous villagers. After nearly two years of practical exploration, Zhengjiawopo Village has realized selfdevelopment to a certain extent with the integrated planning of the village effectively promoted, and has achieved a phased victory in pursuing prosperity and revitalization.

\section{Acknowledgment}

This work was funded by the key Research and Development program of Social Science Plan Foundation of Shandong Province(19CWYJ03); Jinan Philosophy and Social Science Key Project (JNSK20B32).

\section{References}

1. Huang Xuejun. Digital protection and inheritance of traditional cultural heritage from ancient villages . People's Tribune, 2020, (03): 140-141.

2. ang Baohua. Study on the strategy of reconstructing the public space of traditional villages in Chiqiao Village of Taiyuan. Urban Development Studies, 2020, (05): 9-12.

3. Li Qiushan. Analysis on the sustainable development path of traditional settlement of Linpan in western Sichuan from the perspective of genetic inheritance. Areal Research and Development, 2020, 39 (03): 174180.

4. Zheng Guanghui, Jiang Difei, Chen Guolei, Luan Yongfei. Spatial distribution pattern and influence mechanism of key rural tourism villages in China. Journal of Arid Land Resources and Environment, 2020, (09): 194-201.

5. Tu Shuangshuang. Spatio-temporal of rural development and reconstructing and regional path of rural vitalization in Guangxi, China. Acta Geographica Sinica, 2020, (02): 365-381. 